\title{
Measure the Relative Efficiency of a Four-Stage Production Process with NDEA
}

\author{
Claudio Pinto ${ }^{1}$ \\ ${ }^{1}$ DISES, University of Salerno, Via Giovanni Paolo II, 84084 Fisciano (SA), Italy \\ Correspondence: Claudio Pinto, DISES, University of Salerno, Via Giovanni Paolo II, 132, 84048 Fisciano (SA), \\ Italy. E-mail: clpinto@unisa.it
}

Received: July 31, 2020

Accepted: September 2, 2020

Online Published: September 16, 2020

doi:10.5539/ijbm.v15n10p35

URL: https://doi.org/10.5539/ijbm.v15n10p35

\begin{abstract}
The measurement of the relative efficiency of a production process with the DEA approach considers the process itself as a "black box" that uses inputs to produce outputs. In reality, many production processes require the carrying out of many activities grouped into phases and interconnected with each other. For this reason, modeling a production process as a network system in which its sub-parts are differently interconnected certainly represents a modeling closer to reality. The NDEA approach born within the DEA methodology has developed several models to measure the relative efficiency of network systems such as independent models, or connected models or relational models. The latter differs from the other two in that it allows you to measure the relative efficiency of the entire process and its parts once the operations between the parts of the system have been considered. In this paper, as well as modeling a production process with four stages with shared variables, we propose a relational NDEA model under different preference systems in the distribution of resources between sub-processes to measure their relative efficiency. The proposed NDEA model is in the multiplicative version. We will use non-real data to solve the model. Our conclusions are that 1) a four-stage production process can represent numerous real processes, 2) the proposed NDEA model can therefore be used for multiple different applications and 3) the system of preferences on the distribution of resources among subs processes influences the measurement of relative efficiency both for the whole process and for its sub-processes.
\end{abstract}

Keywords: network DEA, performances management, internal structure, inputs-outputs system

\section{Introduction}

Data Envelopment Analysis (DEA) (Cooper, Seiford, \& Tone, 2007) occupies an important role within operational research (RO) and management science (SM) as a frontier non-parametric approach for measuring efficiency relative of a decision-making unit as well as a technique for modeling a system that uses inputs to produce outputs without considering its internal structure. In reality, production processes can be considered as a set of activities often grouped into phases or stages interconnected with each other, such as the production of cars, the production of wine, the production of jewelry, the production of clothes, but also the production of public and private services, and so on. In many of these sectors the applications of DEA have been many numerous [for a review of the literature on DEA applications see (Seiford, 1996), (Emrouznejad, Parker, B., \& Tavares, 2008), (Emrouznejad, A., \& Yang, 2017), (Liu, Lu, Lu, \& Lin, 2013), (Hollingsworth, 2008)] In all DEA applications, decision-making units (or a production process or an entire organization) are modeled as "black boxes" that use inputs to be transformed into outputs. More or less recently, many authors have proposed, always remaining within the DEA methodology, to model the decision-making units as a network system [for example (Fare \& Grosskopf, 2000), (Fa“re R. \&., 1996b), (Kao, 2009(a)), (Castelli, Pesenti, \& Ukovich, 2010), (Castelli, Pesenti, \& Ukovich, 2001)] in which the sub-parts of the system are interconnected with each other. In this last case the measurement of relative efficiency with the DEA can be carried out using different models that consider its internal structure such as independent models [for example (Wang, Gopal, \& Zionts, 1997), (Seiford \& Zhu, 1999), (Sexton \& Lewis, 2003)], or related models [for example (Fa"re \& \& Grosskopf, 1996a), (Fare \& Grosskopf, 2000)]. Differently from the independent models, which treat each part of the system as an independent DEA model, the connected models allow taking into account the operations that occur between interconnected phases but do not, however, allow to measure the efficiency of each single part. Starting from the work of [ (Kao, 2009(a)) (Kao, 2009(b))] a new class of NDEA models have been developed to measure the 
relative efficiency of both the entire process and its parts, taking into account the interconnections. The author defined his approach as a "relational" approach. The characteristics of the relational NDEA approach is that in it the same variables obtain the same weight variable, including the relational variables, so that it is possible to apply a multiplicative decomposition formula of the relative efficiency [ (Kao, 2009(a)) (Kao, 2014)]. In other words, in his work (Kao, 2009 (a)) he allows to obtain the efficiency of the sub-processes from the constraints of the NDEA model and then to obtain the efficiency of the entire process as the product of the individual efficiencies. In his works the author distinguishes models in series, in parallel (as basic models) and then adopts a solution with virtual sub-parts for more complex models [ (Kao, 2009(a)) (Kao, 2009(b)) (Kao, 2014)]. A more general classification for the internal structure of a decision-making unit and the development of related NDEA models to measure its relative efficiency can be found in [ (Castelli, Pesenti, \& Ukovich, 2010)] and his other works. The NDEA approach, however, provides that the modeling (note 1) is adapted to the specific system. NDEA applications are relatively recent but growing [for example (Chodakowska \& Nazarko, 2017), (Kao \& Hwang, 2008), (Kawaguchi, Tone, \& Tsutsui, 2014), (Pinto, 2016), (Prieto \& Zofio, 2007), (Sexton \& Lewis, 2003), (Wanke \& Barros, 2014), (Wanke, Maredza, \& Gupta, 2017), ( (Despotis, Koronakos, \& Sotiros, 2015), (Chilingerian \& Sherman, 2004), (Cook, Hababou, \& Tuenter, 2010)]. In this paper we develop a relational multiplicative type NDEA model assuming constant returns to scale for the entire process and for its parts and with four interconnected subsystems. The paper is structured as follows: in section 2 we offer a broader and more in-depth review of both the theoretical and applied literature of interest, in section 3 we present a graphic model of a system with four subsystems variously interconnected (subsection 3.1) and the related multiplicative type NDEA model (subsection 3.2), in section 4 we offer an example application of the model and finally in section 5 we present the discussion and conclusions.

\section{Material Studied}

The consideration of the internal structure of a production process/organization inside DEA context is relatively recent. A first application can be considered those in (Fa"re \& Whittaker, 1995). In their work the authors adopt a connected NDEA model and their network DEA approach can involve more than two stages and the operations among them. Their work consider an application of an input oriented two-stage DEA model to dairy farms and compare the results obtained with the ones obtained with a standard DEA model. Since the work of (Fa"re \& Whittaker, 1995) other works appeared in the applied economic and managerial literature. For example (Sexton \& Lewis, 2003) apply a two-stages NDEA model to Major League Baseball considering both inputs and outputs orientation and each one under constant and variable return to scale assumptions. In their paper the authors using the envelopment form demonstrate as it is possible to make different assumptions for each sub-process in a context of network system. (Chilingerian \& Sherman, 2004) apply the NDEA approach in a two stage process in measuring a physicians care. (Prieto \& Zofio, 2007) applied network efficiency analysis within an input- output model initiated by (Koopmans, 1951). In their work the authors optimized primary input allocations, intermediate products and final demand products by way of Network DEA techniques and succeeded in applying their models to input-output database of OECD countries. (Kao \& Hwang, Efficiency decomposition in two-stage data envelopment analysis: An application to non-life insurance companies in Taiwan, 2008) introduced for the first time in the context of two-stage network DEA the relational approach. They develop an multiplier input-oriented two-stage DEA model and apply it to measure the relative efficiency of non-life insurance companies in Taiwan. (Wanke \& Barros, Two-stage DEA: An application to major Brazilian banks, 2014) apply the network-DEA centralized efficiency model to optimize efficiency in Brazilian banking in both modelled stages simultaneously. (Wanke, Maredza, \& Gupta, Merger and acquisitions in South African banking: A network DEA model, 2017) apply a network DEA approach to compute the impact of contextual variables on several types of efficiency scores of the resulting virtual merged banks: global (merger), technical (learning), harmony (scope), and scale (size) efficiencies. (Kawaguchi, Tone, \& Tsutsui, 2014) employed a dynamic-network data envelopment analysis model (DN model) to perform the evaluation of the policy effect of the current reform of Japan's municipal hospitals. (Despotis, Koronakos, \& Sotiros, 2015) apply a network DEA approach to deal with efficiency assessments in two-stage processes and apply their approach to the assessment of the academic performance of forty faculty members in a Greek University. (Pinto, 2016) apply both constant and variable returns to scale Data Envelopment Analysis network model to estimates the relational and sub-process efficiency of the production process of the hospital's acute care services. (Chodakowska \& Nazarko, 2017) apply a network DEA models in evaluating courier and messenger companies. In their work the authors consider an hypothetical chains consisting of two types of members, i.e. nine leaders of the courier and messenger sector that had the share of nearly $95 \%$ of total revenue generated from provision of courier services in 2014. The second member was the bigger enterprise in the electronic shopping sector that does not have stationary shops e.g. Bonprix Sp. z o.o. Their approach consider envelopment form. For a review of applications 
of NDEA see (Kao, 2014) and (Cook, Liang, \& Zhu, 2010). (Pinto, 2019) (from which this work comes), model a production process as a network of four sub-processes with shared variables and fixed preferences about the allocation of system resources between them. To measure the relative efficiency of the process and its parts the author develop an input-oriented NDEA model in the multiplier version.. (Pinto, 2020) hypothesized a production process, made up of three interconnected parts ad propose a new strategy to acquire relative efficiency consisting of building a block inside the system with at least two sub-processes. (Pinto, 2020) propose a way to use a relational NDEA model as a policy tool by exploiting the possibility of making assumptions about the model variables.

\section{Method}

\subsection{A General Four Stages Production Process}

In this subsection we are modelling a general production process of four sub-process (see Figure 1).

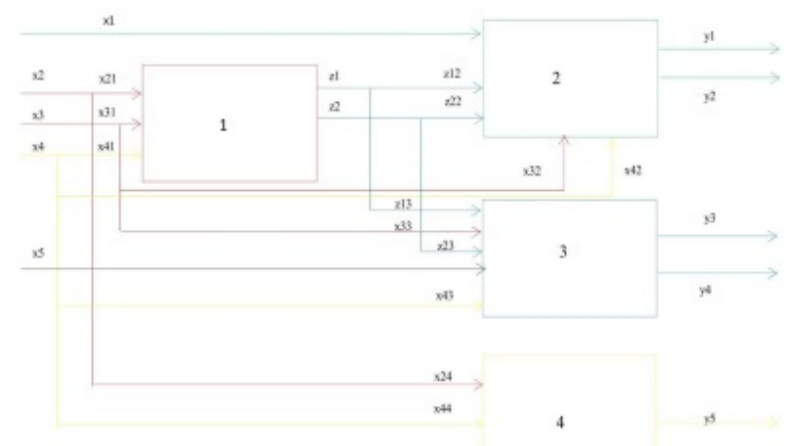

Figure 1. A network system of a production process with four sub-process

The production process in Figure 1 considers four interconnected sub-processes. The process outputs are five $\left(y_{1}, y_{2}, y_{3}, y_{4}, y_{5}\right)$ and the production process inputs are $5\left(x_{1}, x_{2}, x_{3}, x_{4}, x_{5}\right)$, while the intermediate variables (Fa" re \& Whittaker, 1995) are two $\left(z_{1}, z_{2}\right)$. In particular, the first sub-process produces two outputs (the intermediate variables $z_{1}$ and $\left.z_{2}\right)$ where a part of it becomes the inputs of the second sub-process $\left(z_{12}, z_{22}\right)$ and the remaining proportions are the inputs of the third sub-process $\left(z_{13}, z_{23}\right)$. To produce its outputs $\left(y_{5}\right)$ the fourth subprocess uses a proportion of two input systems $\left(x_{24}, x_{44}\right)$, while the second and third sub-processes use an exogenous variable for each ( $x_{1}$ and $x_{5}$ respectively). In summary, the second subprocess to produce its two outputs $\left(y_{1}, y_{2}\right)$ uses one exogenous input variable $\left(x_{1}\right)$, two shared relational variables $\left(z_{12}, z_{22}\right)$ and two shared inputs system $\left(x_{32}, x_{42}\right)$. he third subprocess to produce its two output $\left(y_{3}, y_{4}\right)$ uses an exogenous variable $\left(x_{5}\right)$, two shared relational variables $\left(z_{13}, z_{23}\right)$ and two shared inputs variables $\left(x_{33}, x_{43}\right)$, and finally the fourth sub-process to produce its output $\left(y_{5}\right)$ use two shared inputs variables $\left(x_{24}\right.$ and $\left.x_{44}\right)$. The system has no feedback variables and has no shared outputs [ (Cook, Hababou, \& Tuenter, 2010), (Castelli, Pesenti, \& Ukovich, 2010), (Chen, Du, Sherman, \& Zhu, 2010 b)]. The model is very general and other configurations of inputs, outputs and intermediate variables are possible. So, for example, we can add a second exogenous variable to the second sub-process, or add a third intermediate variable and so on. In the following subsection we construct the relative NDEA model to estimate the relative efficiency of the manufacturing process in Figure 1.

\subsection{The NDEA Model}

In this subsection we build the multiplicative input-oriented relational NDEA model to measure the relational efficiency for the four-step manufacturing process such as those shown in Figure 1 above. The input version of the model, once adopted the linearization suggested by (Charnes \& Cooper, 1962), can be writeen as follow:

$$
\begin{gathered}
\max \sum_{r=1}^{p} u_{r} Y_{\text {ro }} \\
\text { s.t. } \quad \sum_{s=1}^{q} v_{i} X_{i o}=1,
\end{gathered}
$$




$$
\begin{gathered}
\sum_{r=1}^{p} u_{r} Y_{r k}-\sum_{s=1}^{q} v_{i} X_{i k} \leq 0 \\
\sum_{R=1}^{m} w_{r 1 k} Z_{r 1 k}-\sum_{s=1}^{n} v_{r k} X_{r 1 k}^{S} \beta_{j} \leq 0 \\
\sum_{r=1}^{S} u_{r} Y_{r k 2}-\sum_{r=1}^{t} \alpha_{r} w_{r k 2} Z_{r 2 k}^{S}-\sum_{r=1}^{T} \dot{v}_{l} X_{r 2}-\sum_{s=1}^{U} \beta_{s} v_{i} X_{r k 2}^{S} \leq 0 \\
\sum_{r=1}^{Z} Y_{r k 3} u_{r}-\sum_{r=1}^{l} \beta_{s} v_{i} X_{i k 3}^{S}-\sum_{r=1}^{L}\left(1-\alpha_{r}\right) w_{r k 3} Z_{r k 3}^{S}-\sum_{r=1}^{M} v_{i} X_{i k 3} \leq 0 \\
\sum_{r=1}^{o} u_{r} Y_{r k 4}-\sum_{r=1}^{o} v_{r} X_{r k 4}^{S} \leq 0 \\
u, w, v \geq 0
\end{gathered}
$$

Where:

$Y_{r k}=$ are the outputs of the system with $r \in R^{p=5}$ for p outputs system $\left(y_{1}, y_{2}, y_{3}, y_{4}, y_{5}\right)$.

$X_{i k}=$ are the inputs of the system with $i \in R^{q=5}$ for $\mathrm{q}$ inputs system $\left(x_{1}, x_{2}, x_{3}, x_{4}, x_{5}\right)$ including the exogenous variables of the sub-process (in this case the variables $x_{1}, x_{5}$ ).

$Z_{h 1 k}=$ are the outputs of the first sub-process with $h \in R^{m=2}\left(z_{1}\right.$ and $\left.z_{2}\right)$. The pedice 1 indicate the first sub-process.

$X_{i 1 k}=$ are the inputs of the first sub-process $\left(x_{21}, x_{31}, x_{41}\right)$. In our NDEA model all these variables are shared variables and for this reason we adopt the notation $X_{r 1 k}^{S}$.

$Y_{r k 2}=$ are the outputs of the second sub-process $\left(=Y_{r k}\right)\left(y_{1}, y_{2}\right)$. The pedice 2 indicate the second sub-process.

$Z_{p 2 k}^{S}=$ are the relational shared inputs of the second sub-process $\left(z_{12}, z_{22}\right)$

$X_{r 2 k}=$ are the exogenous variables of the second subprocess $\left(x_{1}\right)$.

$X_{r k 2}^{s}=$ are the shared inputs variables of the second sub process $\left(x_{32}, x_{42}\right)$.

$Z_{r k 3}^{S}=$ are the relational shared variables of the third subprocess $\left(z_{13}, z_{23}\right)$.

$X_{r k 3}^{S}=$ are the shared inputs variables of the sub-process three $\left(z_{13}, z_{23}\right)$

$X_{i k 3}=$ are the inputs of the third subprocess $\left(x_{33}, x_{43}\right)$

$Y_{r k 3}=$ are the outputs of the third sub $\operatorname{process}\left(y_{3}, y_{4}\right)$

$Y_{r k 4}=$ are the outputs of the fourty $\operatorname{sub} \operatorname{process}\left(y_{5}\right)$

$X_{i 4 k}=$ are the inputs are of the fourth sub process $\left(x_{24}, x_{44}\right)$

$\mathrm{k}=$ is the number of production units $(\mathrm{k}=1 \ldots \ldots \mathrm{N})$

$\mathrm{u}, \mathrm{v}, \mathrm{w}, \dot{W}=$ are the weight of the model's variables

$\boldsymbol{\beta}\left(\beta_{1}, \beta_{2}, \beta_{3}, \beta_{4}, \beta_{5}, \beta_{6}\right) \quad=$ is the vector of inputs sharing proportions ( $\beta_{1}$ for inputs $2, \beta_{2}$ and $\beta_{3}$ for inputs $3, \beta_{4}$ and $\beta_{5}$ for inputs 4 respectively)

$\boldsymbol{\alpha}\left(\alpha_{1}, \alpha_{2}\right)=$ is the vector of the intermediate variables sharing proportions ( $\alpha_{1}$ for $z 1, \alpha_{2}$ for z2 intermediate variables).

The system has $\mathrm{p}$ outputs $\left(y_{1}, y_{2}, y_{3}, y_{4}, y_{5}\right)$ and $q$ inputs $\left(x_{1}, x_{2}, x_{3}, x_{4}, x_{5}\right)$. Some inputs system (in particular $\left.x_{2}, x_{3}, x_{4}\right)$ are shared among the four sub-process as follows: the first sub-process have $n=3$ shared inputs $\left(x_{21}, x_{31}, x_{41}\right)$ and $m=2$ outputs $\left(z_{1}, z_{2}\right)$, the second sub-process have $s=2$ outputs $\left(y_{1}, y_{2}\right), t=2$ intermediate shared variables $\left(z_{12}, z_{22}\right), U=2$ shared inputs $\left(x_{32}, x_{42}\right)$ and $\mathrm{T}=1$ exogenous variables $\left(x_{1}\right)$, the third subprocess have $z=2$ outputs $\left(y_{3}, y_{4}\right), l=1$ exogenous variables $\left(x_{5}\right), L=2$ intermediate shared variables $\left(z_{13}, z_{23}\right)$ and $M=2$ shared inputs variables $\left(x_{33}, x_{43}\right)$ (with the first subprocess), the fourth subprocess have $o=1$ outputs $\left(y_{5}\right)$ and $O=2$ shared inputs $\left(x_{24}, x_{44}\right)$ (with the first subprocess). The first constraint is the normalization constraint (Charnes \& Cooper, 1962). The second constraint is the system constraint, the third is the first sub-process constraint, and finally, the fourth and five constraints are the third and fourth stage constraints. To 
consider the relationship between the phases / sub-process and treat the model as a relational NDEA model all variables, including relational variables (Z), have the same weights [ (Kao, 2009(a))], and obviously we attach the same weights and the same shared relational variables as well as the same non-relational shared variables (this solution has an obvious computational gain for us). The share ratio is based on the scalar vectors $(\boldsymbol{\beta}, \boldsymbol{\alpha})$. The output version of the NDEA model above is as following:

$$
\begin{gathered}
\min \sum_{s=1}^{q} v_{i} X_{i o} \\
\text { s.t. } \sum_{r=1}^{p} u_{i} Y_{i}=1 \\
\left.-\sum_{r=1}^{p} u_{r} Y_{r k} \mp \sum_{s=1}^{q} v_{i} X_{i k} \geq 0 \text { (Note } 1\right) \\
-\sum_{R=1}^{m} w_{r 1 k} Z_{r 1 k}+\sum_{s=1}^{n} v_{r k} X_{r 1 k} \beta_{j} \geq 0, \\
+\sum_{r=1}^{t} u_{r} Y_{r k 2} \alpha_{r} w_{r k 2} Z_{r 2 k}^{S}+\sum_{r=1}^{T} \dot{w}_{J} X_{r 2}+\sum_{s=1}^{U} \beta_{s} v_{i} X_{r k 2}^{S} \geq 0 \\
-\sum_{r=1}^{Z} Y_{r k 3} u_{r}+\sum_{r=1}^{l} \beta_{s} v_{i} X_{i k 3}^{S}+\sum_{r=1}^{L}\left(1-\alpha_{r}\right) w_{r k 3} Z_{r k 3}^{S}+\sum_{r=1}^{M} v_{i} X_{i k 3} \geq 0 \\
-\sum_{r=1}^{o} u_{r} Y_{r k 4}+\sum_{r=1}^{o} v_{r} X_{r k} \geq 0 \\
u, w, v, \widetilde{w}, \dot{w} \geq 0
\end{gathered}
$$

The output-oriented multiplicative NDEA model in (2) gives us the measure of how much the output of the process can be improved once we consider the relationship between the sub-process within it. As you can see (1) and (2) assume a constant return of scale for the whole system as well as for each sub-process. Figure 1a below illustrates the CRS efficient frontier for sub-process 1 (the straight line $O C^{1}$ ) on the right and the efficient frontier of the CRS for sub-process 2 (straight line $O D$ (note 2)) on the left side.

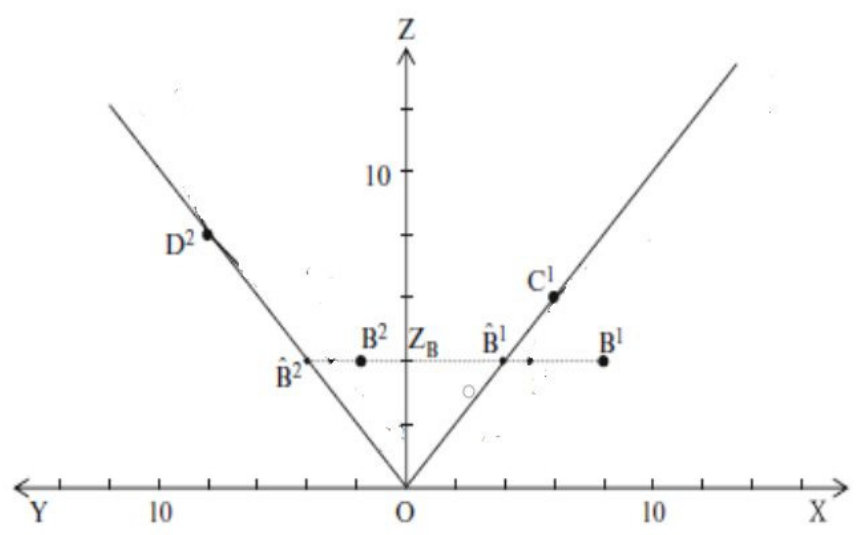

Figure 1a. CRS efficient frontier of first and second sub process

On the right side of the Figure 1a sub-process 1 apply an input vector $\mathrm{X}\left(x_{21}, x_{31}, x_{41}\right)$ to produce a vector of intermediate product $Z\left(z_{1}, z_{2}\right)$, and the left side show a sub-process 2 that applies intermediate product $Z\left(z_{1}, z_{2}\right)$ to produce a vector of outputs $\mathrm{Y}\left(y_{1}, y_{2}\right)$. The superscripts associated with the DMU indicate the subprocess. For example the DMU B is overall inefficient in the first as in the second sub-process. These measure are $\left(\widehat{B^{1}} / Z_{B}\right) /$ 
$\left(B^{1} / Z_{B}\right)$ and $\left(B^{2} / Z_{B}\right) /\left(\widehat{B^{2}} / Z_{B}\right)$, respectively.

\section{Data and results}

In this section we will proceed with the application of the model to a virtual input / output of vector data generated as a random number using the uniform distribution (note 3 ). Once set.seed $=4$ has been fixed in R, we proceed with the calculation of its descriptive statistics (see Table 1 below) (note 4). Our virtual data set consists of 5 inputs (x), 5 outputs (y) and 2 relational variables $(\mathrm{z})$.

Table 1. The data description

\begin{tabular}{lll}
\hline Variables & Descriptive statistic & \\
\hline Inputs & mean & s.d. \\
X1 & 10,41 & 2,86 \\
X2 & 72,55 & 36,61 \\
X3 & 103,98 & 60,88 \\
X4 & 89,37 & 51,34 \\
X5 & 27,21 & 15,25 \\
Outputs & & \\
Y1 & 58,73 & 22,01 \\
Y2 & 131,41 & 44,75 \\
Y3 & 176,3 & 90,71 \\
Y4 & 385,77 & 200,1 \\
Y5 & 30,53 & 16,26 \\
Relational variables & & \\
Z1 & 87,09 & 46,71 \\
Z2 & 54,67 & 31,04 \\
\hline
\end{tabular}

Once the NDEA model has been applied with different preference systems by researchers / managers on the allocation of resources between sub processes (see Table 2), the following results are obtained (see Table 3,4,5 and 6).

Table 2. Managerial/researchers preferences on the allocation of the resources among the sub-process

\begin{tabular}{lllll}
\hline Scalar & System of preferences & & & \\
\hline & 1 & 2 & 3 & 4 \\
$\beta_{1}$ & 0.5 & 0.85 & 0.35 & 0.85 \\
$\beta_{2}$ & 0.3 & 0.5 & 0.2 & 0.6 \\
$\beta_{3}$ & 0.3 & 0.2 & 0.5 & 0.3 \\
$\beta_{4}$ & 0.3 & 0.4 & 0.1 & 0.6 \\
$\beta_{5}$ & 0.2 & 0.2 & 0.3 & 0.1 \\
$\beta_{6}$ & 0.2 & 0.3 & 0.1 & 0.1 \\
$\alpha_{1}$ & 0.5 & 0.4 & 0.7 & 1 \\
$\alpha_{1}$ & 0.5 & 0.4 & 0.4 & 1 \\
\hline
\end{tabular}

The first system of preferences allocates through the parameter $\alpha_{1}$ the relational variable $z_{1}$ in the same proportion between the sub-process $2\left(z_{12}\right)$ and $3\left(z_{13}\right)$ in the proportion of $(50 / 50)$, through the parameter $\alpha_{2}$ the relational variable $z_{2}$ is allocated between the sub-process $2\left(z_{22}\right)$ and $3\left(z_{23}\right)$ in the same proportion $(50 / 50)$. 
The parameter $\beta_{1}$ allocates the variable $x_{2}$ in the same proportions (50/50) between the sub-process $1\left(x_{21}\right)$ and $4\left(x_{24}\right)$, the parameter $\beta_{2}$ and $\beta_{3}$ allocates the variable $x_{3}$ among the sub-process $1\left(x_{31}\right), 2\left(x_{32}\right)$ and $3\left(x_{33}\right)$ in the following proportions $0.3,0.3$ and $(1-0.3-0.3)=0.4$, respectively, finally the parameters $\beta_{4}, \beta_{5}$ and $\beta_{6}$ allocates the variable $x_{4}$ among the sub-process $1\left(x_{41}\right), 2\left(x_{42}\right), 3\left(x_{43}\right)$ and $4\left(x_{44}\right)$ in the following proportions $0.3,0.2,0.2$ and $(1-0.3-0.2-0.2)=0.3$, respectively. The second system of preferences allocates through the parameter $\alpha_{1}$ the relational variable $z_{1}$ in the proportions of $(40,60)$ between the sub-process $2\left(z_{12}\right)$ and $3\left(z_{13}\right)$, through the parameter $\alpha_{2}$ allocates the relational variable $z_{2}$ between the sub-process $2\left(z_{23}\right)$ and $3\left(z_{33}\right)$ in the proportions of $(40 / 60)$. The parameter $\beta_{1}$ allocates the variable in the proportions $(0.85 / 0.15)$ between the sub-process $1\left(x_{21}\right)$ and $4\left(x_{24}\right)$, the parameters $\beta_{2}$ and $\beta_{3}$ allocate the variable $x_{3}$ among the sub-process $1\left(x_{31}\right), 2\left(x_{32}\right)$ and $3\left(x_{33}\right)$ in the following proportions $0.3,0.3$ and $(1-0.3-0.3)=0.4$, respectively finally the parameters $\beta_{4}, \beta_{5}$ and $\beta_{6}$ allocates the variable $x_{4}$ among the sub-process $1\left(x_{41}\right), 2\left(x_{42}\right), 3\left(x_{43}\right)$ and $4\left(x_{44}\right)$ in the following proportions $0.3,0.2,0.2$ and $(1-0.3-0.2-0.2)=0.3$, respectively. The third system of preferences allocates through the parameter $\alpha_{1}$ the relational variable $z_{1}$ in the proportions of $(0.7 / 0.3)$ between the sub-process $2\left(z_{12}\right)$ and $3\left(z_{13}\right)$, through the parameter $\alpha_{2}$ allocates the relational variable $z_{2}$ between the sub-process $2\left(z_{22}\right)$ and $3\left(z_{23}\right)$ in the proportions of $(0.4 / 0.6)$. The parameter $\beta_{1}$ allocates the variable $x_{2}$ in the proportions of $(0.35 / 0.65)$ between the sub-process $1\left(x_{21}\right)$ and $4\left(x_{24}\right)$, the parameters $\beta_{2}$ and $\beta_{3}$ allocates the variable $x_{3}$ among the sub-process $1\left(x_{31}\right), 2\left(x_{32}\right)$ and $3\left(x_{33}\right)$ in the following proportions $0.2,0.5$ and (1-0.2-0.5) $=0.2$, respectively. Finally, the parameters $\beta_{4}, \beta_{5}$ and $\beta_{6}$ allocates the variable $x_{4}$ among the sub-process $1\left(x_{41}\right), 2\left(x_{42}\right), 3\left(x_{43}\right)$ and $4\left(x_{44}\right)$ in the following proportions 0.1 , $0.3,0.1$ and $(1-0.1-0.3-0.1)=0.5$, respectively. In the first system of preferences, managers express a more balanced allocation of the outputs of the first sub-process between sub-processes 3 and 4 than in the third system. In other words, managers evaluate with equilibrium the interrelation between sub-processes 1,2 and 3, while in the third, managers consider the second sub-process as a sub-process with a higher consumption of the relational resources produced by the first sub-process. A moderate imbalance in the allocations of relational variables characterizes the second system of preferences. The second, on the other hand, is characterized by the imbalance in the allocation of variable 2 between sub-process 2 and 4, and the third by the unbalance in the allocation of variable $x_{4}$, that privilege the sub-process 4 in its allocation. Finally, the fourth system of preferences radically changes the role of relational variables, now the outputs of the first sub-process are totally intermediate variables for the second sub-process, so it has lost the characteristic of variables shared with the third sub-process, which will now use only a part of the inputs of the system (the variables $x_{3}$ and $x_{4}$. Following the four system of preferences the relative efficiency of the system and of its sub-process will be those reported in the Tables $3,4,5$ and 6.

Table 3. Efficiency estimation (Preferences system 1)

\begin{tabular}{|c|c|c|c|c|c|c|}
\hline \multirow[b]{2}{*}{ Efficiency } & & \multicolumn{5}{|c|}{ Descriptive statistics } \\
\hline & & mean & s.d. & median & I Q(25\%) & IIIQ(75\%) \\
\hline & Obs & \multicolumn{5}{|c|}{ Input oriented measurement } \\
\hline Relational efficiency & 150 & 0,830525 & 0,186378 & 0,884463 & 0,681019 & 1 \\
\hline $\begin{array}{ll}\text { Calculated } & \text { relational } \\
\text { efficiency } & \end{array}$ & 150 & 0,830525 & 0,186378 & 0,884463 & 0,681019 & 1 \\
\hline First sub process efficiency & 147 & 148,6852 & 230.9413 & 70,87663 & 21,81416 & 194,2922 \\
\hline $\begin{array}{l}\text { Second } \\
\text { efficiency }\end{array}$ & 150 & 0,333558 & 0,685407 & 0,076669 & 0,026964 & 0,212165 \\
\hline Third sub-process efficiency & 150 & 0,160628 & 0,187252 & 0,084133 & 0,038834 & 0,211517 \\
\hline $\begin{array}{l}\text { Fourth sub-process } \\
\text { efficiency }\end{array}$ & 150 & 0,233376 & 0,362507 & 0,123434 & 0 & 0,288108 \\
\hline & & \multicolumn{5}{|c|}{ Output oriented measurement } \\
\hline Relational efficiency & 150 & 0,131051 & 0,083731 & 0,113904 & 0,070589 & 0,172138 \\
\hline $\begin{array}{l}\text { Calculated } \\
\text { efficiency }\end{array}$ & 150 & 0,131051 & 0,083731 & 0,113904 & 0,070589 & 0,172138 \\
\hline First sub process efficiency & 150 & 0,078706 & 0,133399 & 0,033797 & 0,017131 & 0,092712 \\
\hline $\begin{array}{l}\text { Second } \\
\text { efficiency }\end{array}$ & 141 & 2,596546 & 6,536574 & 0,729086 & 0,457538 & 1,141824 \\
\hline Third sub-process efficiency & 148 & 2,104779 & 5,713056 & 0,398516 & 0 & 1,71706 \\
\hline $\begin{array}{l}\text { Fourth } \\
\text { efficiency }\end{array}$ & 76 & 0,018975 & 0,044954 & 0,003759 & 0 & 0,018601 \\
\hline
\end{tabular}


Table 4. Efficiency estimation (Preferences system 2)

\begin{tabular}{|c|c|c|c|c|c|c|}
\hline \multirow[b]{2}{*}{ Efficiency } & \multirow[b]{2}{*}{ Obs } & \multicolumn{4}{|c|}{ Descriptive statistics } & \multirow[b]{2}{*}{ IIIQ $(75 \%)$} \\
\hline & & mean & s.d. & median & I Q $(25 \%)$ & \\
\hline & & \multicolumn{4}{|c|}{ Input oriented measurement } & \\
\hline Relational efficiency & 150 & 0,829052 & 0,186871 & 0,884463 & 0,680454 & 1 \\
\hline Calculated relational efficiency & 150 & 0,829052 & 0,186871 & 0,884463 & 0,680454 & 1 \\
\hline First sub process efficiency & 147 & 92,799 & 179,178 & 34,314 & $12,0,93$ & 90,659 \\
\hline Second sub-process efficiency & 150 & 0,36926 & 0,722343 & 0,099617 & 0,034076 & 4,349306 \\
\hline Third sub-process efficiency & 150 & 0,161123 & 0,194164 & 0,081659 & 0,039466 & 0,937963 \\
\hline \multirow[t]{2}{*}{ Fourth sub-process efficiency } & 150 & 0,241008 & 0,359038 & 0,13812 & 0 & 2 \\
\hline & & \multicolumn{3}{|c|}{ Output oriented measurement } & & \\
\hline Relational efficiency & 150 & 0,131051 & 0,083731 & 0,113904 & 0,070589 & 0,172138 \\
\hline Calculated relational efficiency & 150 & 0,131051 & 0,083731 & 0,113904 & 0,070589 & 0,172138 \\
\hline First sub process efficiency & 150 & 0,078706 & 0,133399 & 0,033797 & 0,017131 & 0,092712 \\
\hline Second sub-process efficiency & 138 & 1,05 & 2,144 & 0,772125 & 0,788 & 1,927 \\
\hline Third sub-process efficiency & 82 & 0,049982 & 0,075322 & 0,021215 & 0 & 0,0788 \\
\hline Fourth sub-process efficiency & 76 & 0,018975 & 0,044954 & 0,003759 & 0 & 0,0186 \\
\hline
\end{tabular}

Table 5. Efficiency estimation (Preferences system 3)

\begin{tabular}{|c|c|c|c|c|c|c|}
\hline \multirow[b]{2}{*}{ Efficiency } & \multirow[b]{2}{*}{ Obs. } & \multicolumn{5}{|c|}{ Descriptive statistics } \\
\hline & & mean & s.d. & median & $I Q(25 \%)$ & $\begin{array}{l}I I I Q \\
(75 \%)\end{array}$ \\
\hline \multicolumn{7}{|c|}{ Input oriented measurement } \\
\hline Relational efficiency & 150 & 0,831071 & 0,185908 & 0,884463 & 0,68126 & 1 \\
\hline $\begin{array}{l}\text { Calculated relational } \\
\text { efficiency }\end{array}$ & 150 & 0,831071 & 0,185908 & 0,884463 & 0,68126 & 1 \\
\hline First sub process efficiency & 147 & 158,8529 & 299,333 & 67,9760 & 24,092 & 181,448 \\
\hline Second sub-process efficiency & 150 & 0,250094 & 0,435956 & 0,084716 & 0,033912 & 0,248641 \\
\hline Third sub-process efficiency & 150 & 0,148958 & 0,171433 & 0,078124 & 0,043175 & 0,208608 \\
\hline Fourth sub-process efficiency & 150 & 0,242129 & 0,355655 & 0,139277 & 0 & 0,307079 \\
\hline \multicolumn{7}{|c|}{ Output oriented measurement } \\
\hline Relational efficiency & 150 & 0,131051 & 0,083731 & 0,113904 & 0,070589 & 0,172138 \\
\hline $\begin{array}{l}\text { Calculated relational } \\
\text { efficiency }\end{array}$ & 150 & 0,131051 & 0,083731 & 0,113904 & 0,070589 & 0,172138 \\
\hline First sub process efficiency & 150 & 0,078706 & 0,133399 & 0,033797 & 0,004885 & 0,02357 \\
\hline Second sub-process efficiency & 150 & 0,7608 & 2,010 & 0,39914 & 0,18386 & 0,69647 \\
\hline Third sub-process efficiency & 150 & 0,050295 & 0,075452 & 0,02217 & 0 & 0,072741 \\
\hline Fourth sub-process efficiency & 150 & 0,018975 & 0,044954 & 0,003759 & 0 & 0,018601 \\
\hline
\end{tabular}


Table 6. Efficiency estimation (Preferences system 4)

\begin{tabular}{|c|c|c|c|c|c|c|}
\hline \multirow[b]{2}{*}{ Efficiency } & & \multicolumn{5}{|c|}{ Descriptive statistics } \\
\hline & & mean & s.d. & median & I Q $(25 \%)$ & IIIQ(75\%) \\
\hline & Obs. & \multicolumn{5}{|c|}{ Input oriented measurement } \\
\hline Relational efficiency & 150 & 0,733114 & 0,227461 & 0,721897 & 0,574061 & 0,984066 \\
\hline $\begin{array}{ll}\text { Calculated } & \text { relational } \\
\text { efficiency } & \end{array}$ & 150 & 0,733114 & 0,227461 & 0,721897 & 0,574061 & 0,984066 \\
\hline First sub process efficiency & 142 & 68,876 & 136.879 & 21,014 & 4,985 & 63,499 \\
\hline $\begin{array}{l}\text { Second } \\
\text { efficiency }\end{array}$ & 150 & 0,421303 & 0,945323 & 0,110512 & 0,052987 & 0,313501 \\
\hline Third sub-process efficiency & 150 & 0,115892 & 0,184034 & 0,028536 & 0,000974 & 0,154049 \\
\hline \multirow[t]{2}{*}{ Fourth sub-process efficiency } & 150 & 0,270046 & 0,386234 & 0,156098 & 0 & 0,375528 \\
\hline & & \multicolumn{5}{|c|}{ Output oriented measurement } \\
\hline Relational efficiency & 150 & 0,131051 & 0,083731 & 0,113904 & 0,070589 & 0,172138 \\
\hline $\begin{array}{ll}\text { Calculated } & \text { relational } \\
\text { efficiency } & \end{array}$ & 150 & 0,131051 & 0,083731 & 0,113904 & 0,070589 & 0,172138 \\
\hline First sub process efficiency & 150 & 0,078706 & 0,133399 & 0,033797 & 0,017131 & 0,0927 \\
\hline $\begin{array}{ll}\text { Second } & \text { sub-process } \\
\text { efficiency } & \end{array}$ & 82 & 0,256 & 0,16520 & 0,2322 & 0,12992 & 0,37127 \\
\hline Third sub-process efficiency & 141 & 0,0943 & 0,0847 & 0,07131 & 0,03457 & 0,13199 \\
\hline Fourth sub-process efficiency & 150 & 0,034205 & 0,056005 & 0,0161 & 0,005218 & 0,0328 \\
\hline
\end{tabular}

The cell "Calculated relational efficiency" contain the relative efficiency of the whole process calculated the multiplicative formula (Kao, 2009(a)) once solved the model NDEA in (1). While the cell with "Calculated ...sup-process" contain the result of the application of the decomposition formula for calculating the efficiency of each sub-process (Kao, 2009(a)) once solved the NDEA model in (1). The differences in the measurements are outlined to the comparison among the empirical cumulative distribution of the efficiency scores in the Figures 1,2,3 and 4. The graph refer to the relational efficiency (not calculated) of the whole process and the efficiency of the four sub-process 1,2 under the four system of preferences.
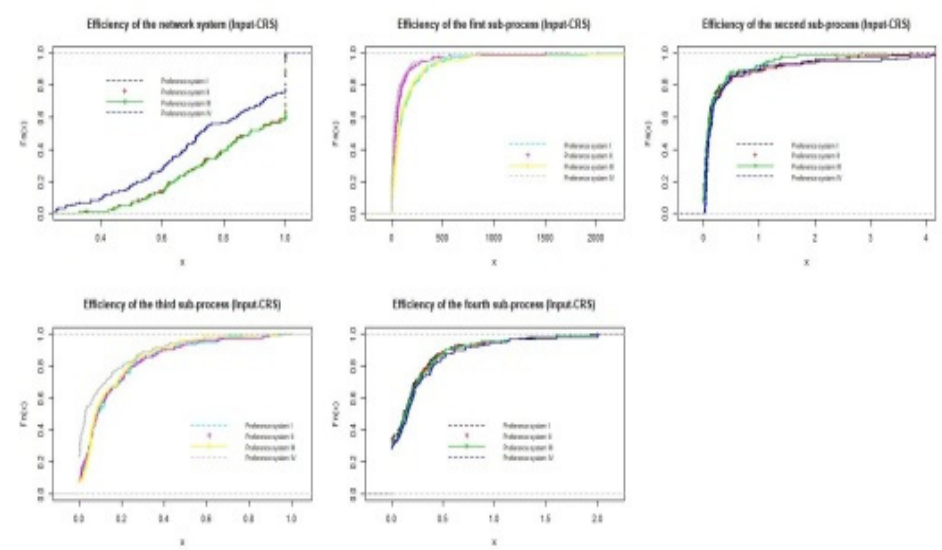

Figure 2. Ecdf of the efficiency scores in the case of CRS-Input orientation 

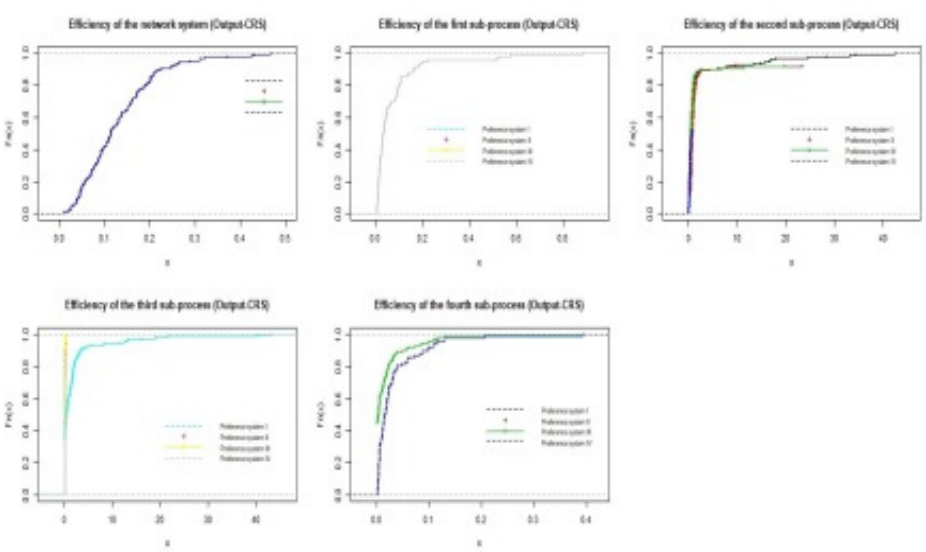

Figure 3. Ecdf of the efficiency scores in the case of CRS-Output orientation

The degree of correlation between the efficiency of each thread can be related to the allocation of resources between them. In the following tables we report the correlation analysis (note 5).

Table 7. CRS- efficiency scores correlations

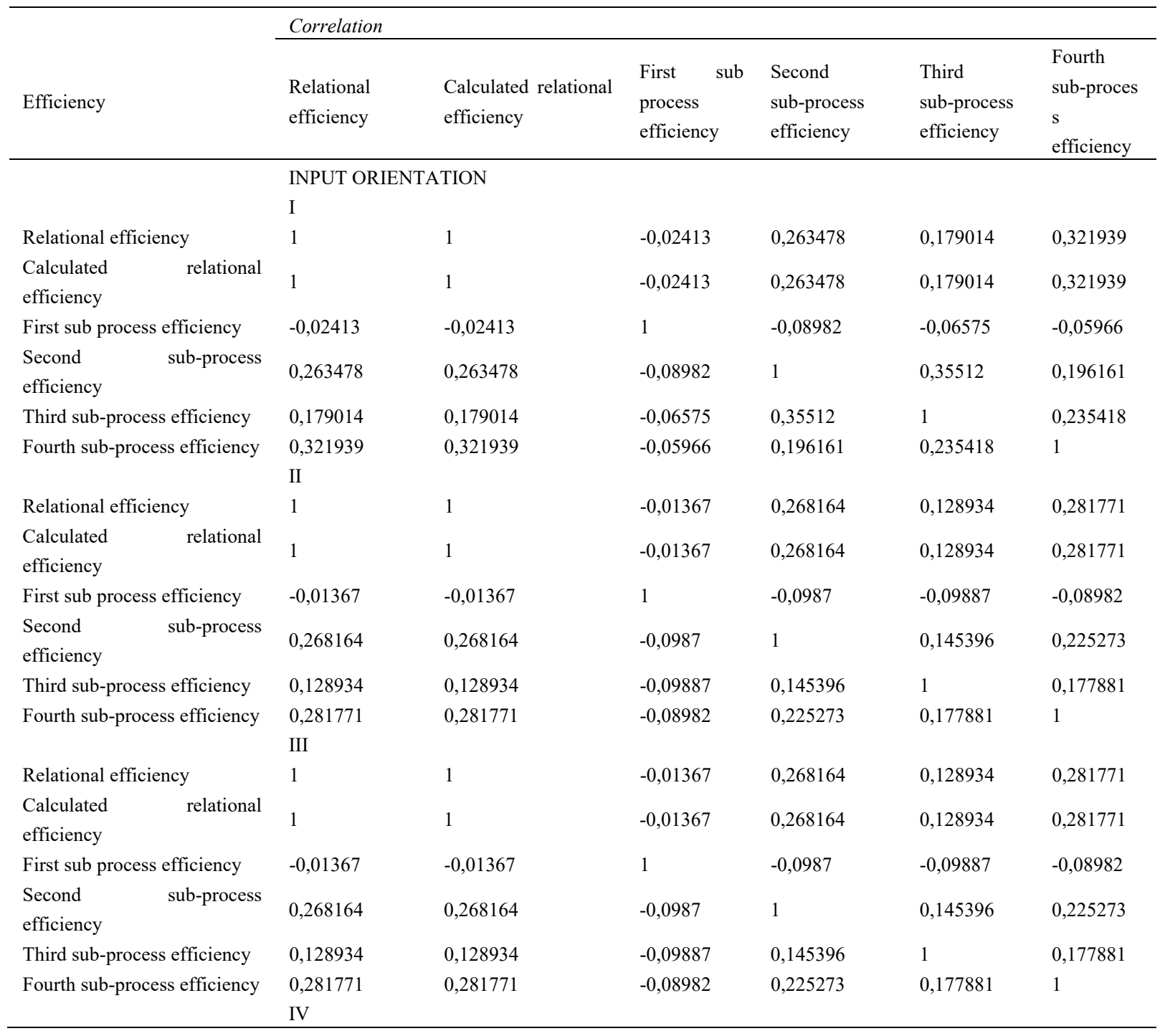




\begin{tabular}{|c|c|c|c|c|c|c|}
\hline Relational efficiency & 1 & 1 & $-0,0094$ & 0,2068 & 0,170763 & 0,203507 \\
\hline $\begin{array}{l}\text { Calculated relational } \\
\text { efficiency }\end{array}$ & 1 & 1 & $-0,0094$ & 0,2068 & 0,170763 & 0,203507 \\
\hline First sub process efficiency & $-0,0094$ & $-0,0094$ & 1 & $-0,14678$ & $-0,08184$ & $-0,10184$ \\
\hline $\begin{array}{l}\text { Second } \quad \text { sub-process } \\
\text { efficiency }\end{array}$ & 0,2068 & 0,2068 & $-0,14678$ & 1 & 0,191021 & 0,047469 \\
\hline Third sub-process efficiency & 0,170763 & 0,170763 & $-0,08184$ & 0,191021 & 1 & $-0,01198$ \\
\hline Fourth sub-process efficiency & 0,203507 & 0,203507 & $-0,10184$ & 0,047469 & $-0,01198$ & 1 \\
\hline & $\begin{array}{l}\text { OUTPUT } \\
\text { I }\end{array}$ & TATION & & & & \\
\hline Relational efficiency & 1 & 1 & 0,258596 & 0,092688 & 0,099812 & 0,243368 \\
\hline $\begin{array}{l}\text { Calculated } \\
\text { efficiency }\end{array}$ & 1 & 1 & 0,258596 & 0,092688 & 0,099812 & 0,243368 \\
\hline First sub process efficiency & 0,258596 & 0,258596 & 1 & $-0,1991$ & $-0,20888$ & 0,0949 \\
\hline $\begin{array}{l}\text { Second } \quad \text { sub-process } \\
\text { efficiency }\end{array}$ & 0,092688 & 0,092688 & $-0,1991$ & 1 & 0,608915 & $-0,20888$ \\
\hline Third sub-process efficiency & 0,099812 & 0,099812 & $-0,20888$ & 0,608915 & 1 & $-0,15114$ \\
\hline Fourth sub-process efficiency & $\begin{array}{l}0,243368 \\
\text { II }\end{array}$ & 0,243368 & 0,0949 & $-0,20888$ & $-0,15114$ & 1 \\
\hline Relational efficiency & 1 & 1 & 0,258596 & \#NUM! & 0,701031 & 0,243368 \\
\hline $\begin{array}{l}\text { Calculated } \\
\text { efficiency }\end{array}$ & 1 & 1 & 0,258596 & \#NUM! & 0,701031 & 0,243368 \\
\hline First sub process efficiency & 0,258596 & 0,258596 & 1 & \#NUM! & 0,407389 & 0,0949 \\
\hline $\begin{array}{l}\text { Second } \quad \text { sub-process } \\
\text { efficiency }\end{array}$ & \#NUM! & \#NUM! & \#NUM! & 1 & \#NUM! & \#NUM! \\
\hline Third sub-process efficiency & 0,701031 & 0,701031 & 0,407389 & \#NUM! & 1 & 0,352086 \\
\hline Fourth sub-process efficiency & $\begin{array}{l}0,243368 \\
\text { III }\end{array}$ & 0,243368 & 0,0949 & \#NUM! & 0,352086 & 1 \\
\hline Relational efficiency & 1 & 1 & 0,307872 & \#NUM! & 0,927164 & \#NUM! \\
\hline $\begin{array}{l}\text { Calculated relational } \\
\text { efficiency }\end{array}$ & 1 & 1 & 0,307872 & \#NUM! & 0,927164 & \#NUM! \\
\hline First sub process efficiency & 0,307872 & 0,307872 & 1 & \#NUM! & 0,347914 & \#NUM! \\
\hline $\begin{array}{l}\text { Second } \quad \text { sub-process } \\
\text { efficiency }\end{array}$ & \#NUM! & \#NUM! & \#NUM! & 1 & \#NUM! & \#NUM! \\
\hline Third sub-process efficiency & 0,927164 & 0,927164 & 0,347914 & \#NUM! & 1 & \#NUM! \\
\hline Fourth sub-process efficiency & $\begin{array}{l}\text { \#NUM! } \\
\text { IV }\end{array}$ & \#NUM! & \#NUM! & \#NUM! & \#NUM! & 1 \\
\hline Relational efficiency & 1 & 1 & 0,307872 & 0,118829 & 0,927164 & 0,295091 \\
\hline $\begin{array}{l}\text { Calculated relational } \\
\text { efficiency }\end{array}$ & 1 & 1 & 0,307872 & 0,118829 & 0,927164 & 0,295091 \\
\hline First sub process efficiency & 0,307872 & 0,307872 & 1 & 0,015969 & 0,347914 & 0,036728 \\
\hline $\begin{array}{l}\text { Second } \quad \text { sub-process } \\
\text { efficiency }\end{array}$ & 0,118829 & 0,118829 & 0,015969 & 1 & 0,116996 & 0,110918 \\
\hline Third sub-process efficiency & 0,927164 & 0,927164 & 0,347914 & 0,116996 & 1 & 0,269173 \\
\hline Fourth sub-process efficiency & 0,295091 & 0,295091 & 0,036728 & 0,110918 & 0,269173 & 1 \\
\hline
\end{tabular}

The correlation analysis reported in Table 7, among other possible observations, highlights that the efficiency of the first sub-process is, albeit slightly, negatively correlated with the efficiency scores of all the remaining sub-processes under all the different allocation systems of intra-process resources. While the efficiency of the second sub-process is positively correlated with the efficiency of the third sub-process although its correlation with the third sub-process is greater under the first system (0.35) of preferences than all other systems of preferences $(0.145,0.145$ and 0.191 respectively under the second, third and fourth). The latter is also the highest positive correlation we observe in Table 7 . While the lowest positive correlation is $\cong 0.0475$ and occurs between the fourth and second sub-processes under the fourth preference system. In Figure 2 below we report the path of efficiencies. 


\subsection{Which System of Preferences?}

The goal of the empirical application is to measure the relative efficiency of the whole system and its parts. Another goal is to compare the effect of preference systems on the measurement of relative efficiency. In principle, for researchers / managers, a system of preference for allocating resources between sub-processes that allows for greater relative efficiency of process and sub-process is preferable to any other. Here, we will show the results of the Wilcoxon-Mann-Whitney test (note 6) once we have verified that the data (the vectors of our efficiency scores) do not belong to the normal distribution (note 7) and that their variance is homogeneous (note 8). All test results allow us to infer that the calculated efficiency scores do not belong to a normal distribution, that their variances are homogeneous, that the relational efficiency scores in preference system 1, 2 and 3 come from the same distribution, and that the 'Relational efficiency scores with preference system 4 do not belong to the same distributions as systems 1,2 and 3. The results are in Table 7 below.

Table 8. Wilcoxon-Mann-Whitney test

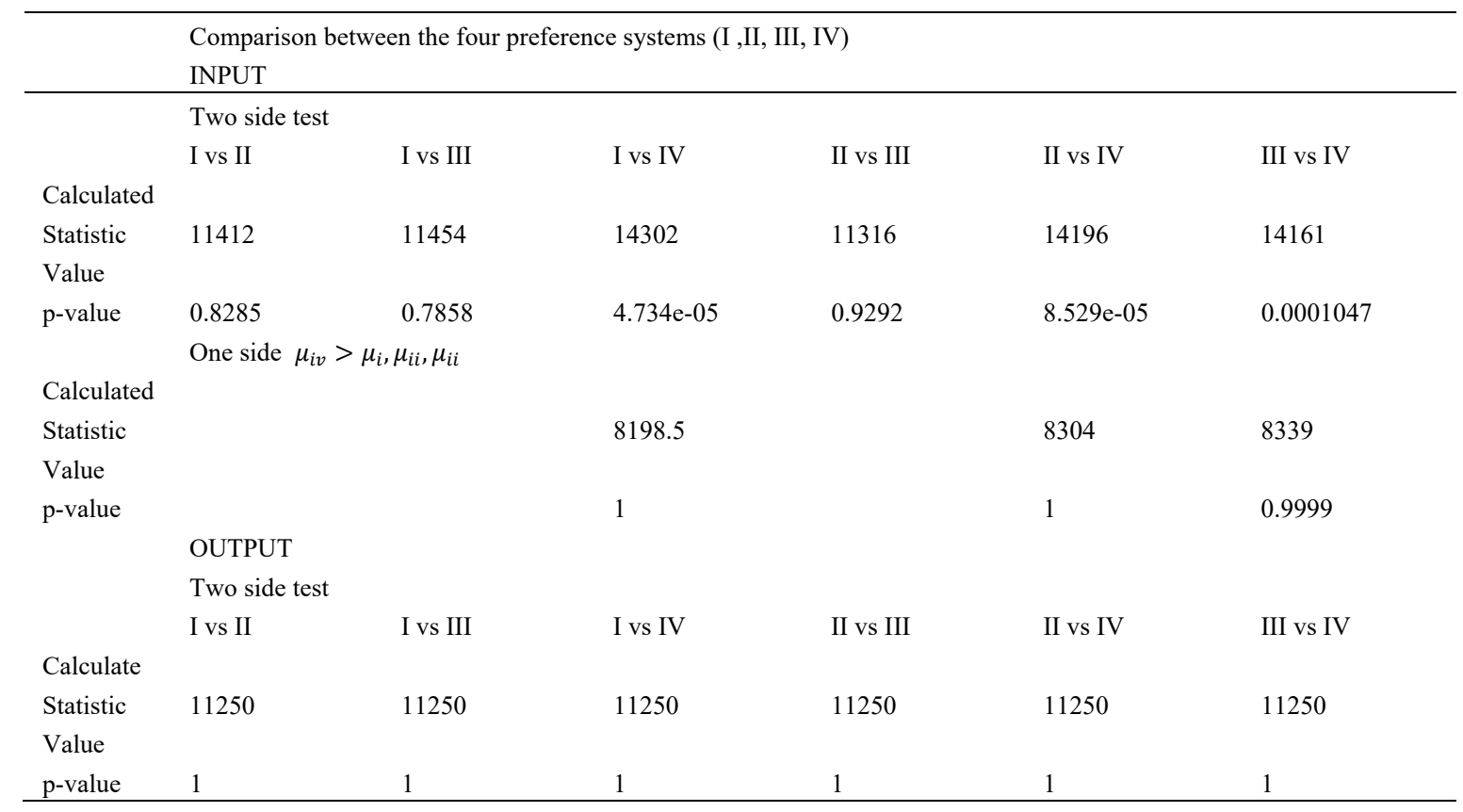

As we can see, in the case of input measurement, the preference system IV would be preferred because the average of the relational efficiency of the whole process (see Figure 2) is larger than the average of the relational efficiency estimates under the remaining preference systems (see the values of the p-values in the case of One side test (note 9) in Table 7). Instead, in the case of output measurement there are no statistically significant differences in the relative efficiency scores of the entire process. Differences appear at level of sub-process efficiency (see the plot on ecdf Figures 2 ). Yet, in the case of output orientation measurement there are no differences in the distributions (see Figure 3). 


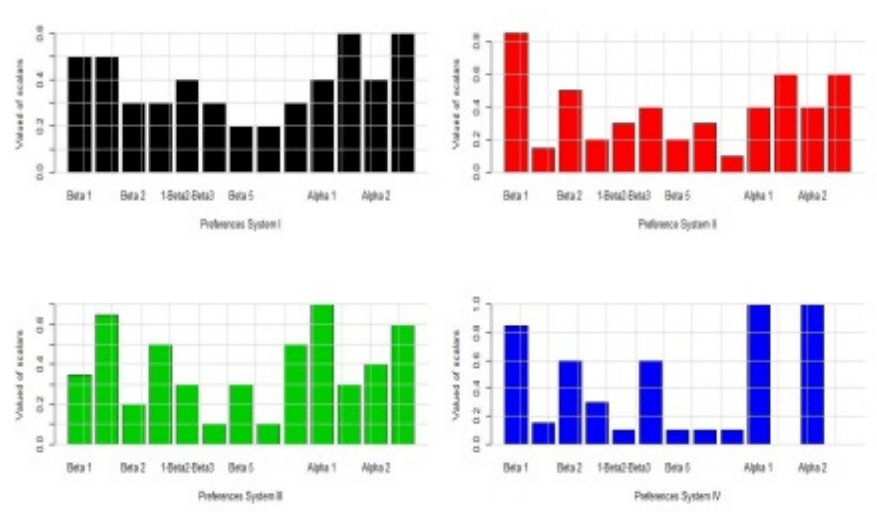

Figure 4. Barplot of the scalars

The plot of the efficiency scores are in Figure 5 and 6 , while the comparison of the system preferences are in Figure 4.
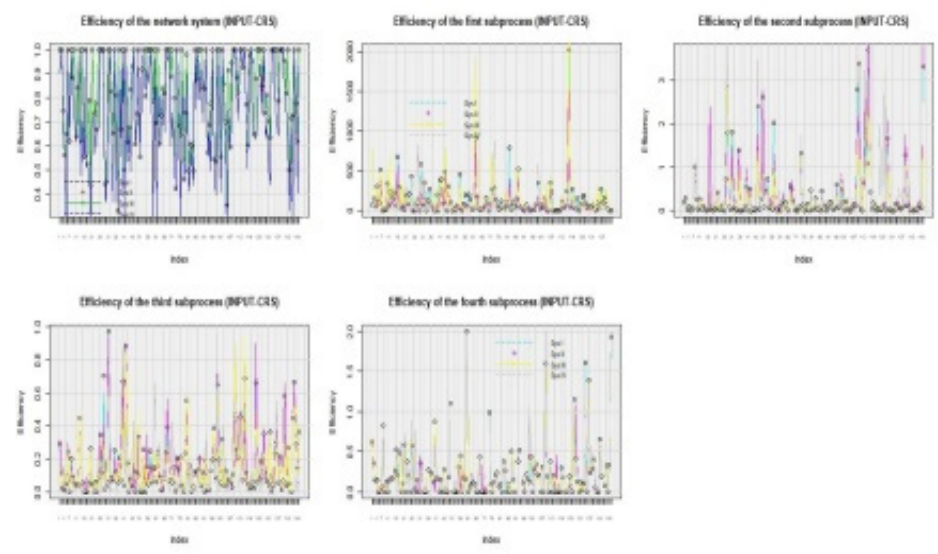

Figure 5. Simple plot input CRS
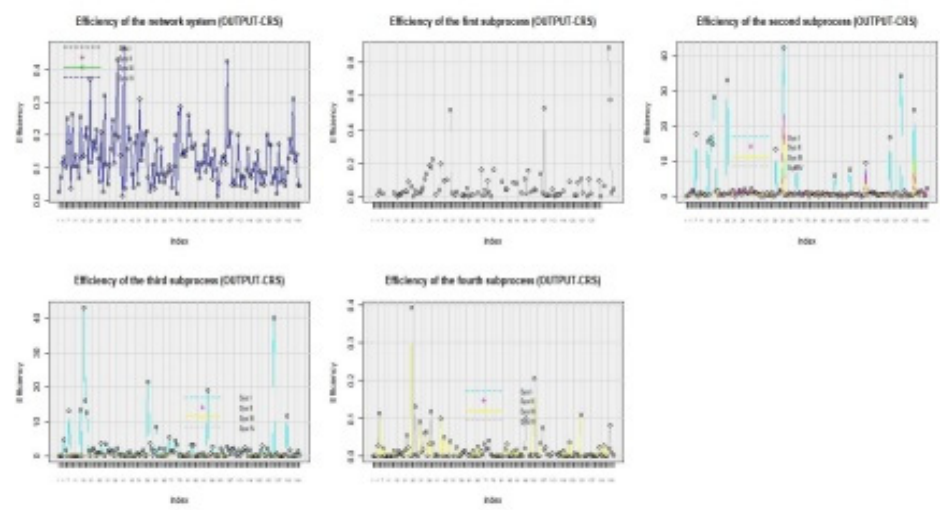

Figure 6. simple plot output CRS

\section{Discussion}

The paper developed a relational NDEA model in the multiplicative version to measure the efficiency of a generic production process modeled as a system composed of four interconnected sub-processes. The measurement was conducted for both input orientation and output orientation, assuming constant returns to scale 
(CRS) for both the entire system and its sub-parts. The interrelationships of the sub-processes of the system were defined on the author's discretion without any reference to real processes. In particular, the model considered shared intermediate variables between sub-processes 1 and $2\left(z_{12}, z_{23}\right)$ and between sub-processes 1 and 3 $\left(z_{13}, z_{23}\right)$. The configuration of the interrelations can be modified by acting on the system of intra-system resource allocation weights as done with system IV. With this last allocation system, for example, sub-process 3 no longer has shared relational variables but is sharing its inputs with sub-process 1 . If the objective is to increase the outputs of the system the output-NDEA model should be solved. All the NDEA models presented here have been solved with the simplex method. The application show that when we adopt the same weights for the same variables in the model (in other words we estimate a relational NDEA model [ (Kao, 2009(a)), (Kao, 2009(b)) (Kao, 2014)]) the relative efficiency of the sub-process can be calculated applying the multiplicative decomposition formula proposed by (Kao, 2009(a)) and the sources of inefficiency can be individuated at sub-process level. The characteristic of our model is that the proportion of resources that sub-process are sharing is defined apriori to the researcher or/and manager of the organization where the process is running. This is traducing in the apriori fixing of the vector parameters $\boldsymbol{\alpha}$ and $\boldsymbol{\beta}$ of our model. This leaves the researcher/manager to define his preferences about the proportions of resources to be allocated to each sub-process. In other words, the latter parameters are assigned exogenously rather than being calculated endogenously inside the NDEA model. The interpretation of the optimal weights is the same as that given in the standard DEA models, they represent the contribution of the resource to the improvement of the relative efficiency of the sub-process as that of the process. The estimation of relative efficiency (see Table 3,4,5 and 6) through our NDEA model is strictly dependent on preferences (see Table 2) on the distribution of resources among the sub-processes defined by the researcher. Unlike the literature on the topics, the document develops a four-step system process, sharing all the limitations and advantages of the relational NDEA approach. However, we believe that the model proposed here covers a wide range of real-world manufacturing processes, so the NDEA model developed here can be applied for many applications with real data.

\section{Conclusion}

We can conclude in that the paper offers, in our opinion, a wide possibility to conduct relative efficiency analysis research for 4-stage production processes using the NDEA methodology. The paper also shows how it is possible to define an intra-system resource allocation system based both on managerial preferences and deriving from objective internal and / or external needs.

\section{References}

Castelli, L., Pesenti, R., \& Ukovich, W. (2001). DEA-like models for efficiency evaluations of specialized and interdependent units. European Journal of Operational Research, 132(2), 274-286. https://doi.org/10.1016/S0377-2217(00)00151-X

Castelli, L., Pesenti, R., \& Ukovich, W. (2010). A classification of DEA models when the internal structure of the Decision Making Units is considered. Annals of Operations Research, 173, 207-235. https://doi.org/10.1007/s10479-008-0414-2

Charnes, A., \& Cooper, W. (1962). Programming with Linear Fractional Functionals. Naval Research Logistics Quarterly, 2, 181-185. https://doi.org/10.1002/nav.3800090303

Chen, Y., Du, J., Sherman, H. D., \& Zhu, J. (2010 b). DEA model with shared resources and efficiency decomposition. European Journal of Operational Research, 207, 339-349. https://doi.org/10.1016/j.ejor.2010.03.031

Chilingerian, J., \& Sherman, H. D. (2004). Health care applications: From Hospitals to Physician, from productive efficiency to quality frontiers. In L. M. W. W. Cooper, Handbook on data envelopment analys. Boston: Springer. https://doi.org/10.1007/978-1-4419-6151-8_16

Chodakowska, E., \& Nazarko, J. (2017). Network DEA Models for Evaluating Couriers and Messengers. Procedia Engineering, 182, p. 106-111. https://doi.org/10.1016/j.proeng.2017.03.130

Cook, W., Hababou, M., \& Tuenter, H. (2010). Multicomponent efficiency measurement and shared inputs in data envelopment analysis: An application to sales and service performance in bank branches. Journal of Productivity Analysis, 14(3), p. 209-224. https://doi.org/10.1023/A:1026598803764

Cook, W., Liang, L., \& Zhu, J. (2010). Measuring performance of two-stage network structures by DEA: A review and future perspective. Omega, 38(6), 423-430. https://doi.org/10.1016/j.omega.2009.12.001 
Cooper, W. W., Seiford, L. M., \& Tone, K. (2007). Data Envelopment Analysis. A Comprehensive Text with Models, Application, References and DEA-Solver Software. New York: Springer. https://doi.org/10.1007/978-0-387-45283-8

Despotis, D., Koronakos, G., \& Sotiros, D. (2015). A Multi-objective Programming Approach to Network DEA with an Application to the Assessment of the Academic Research Activity. Procedia Computer Science, Procedia Computer Science, Volume 55, 2015, Pages 370-379, 370-379. https://doi.org/10.1016/j.procs.2015.07.070

Emrouznejad, A., \& Yang, G. (2017). A survey and analysis of the first 40 years of scholarly literature in DEA: 1978e2016. Socio-Economic Planning Sciences, 1-5. https://doi.org/10.1016/j.seps.2017.01.008

Emrouznejad, A., Parker, B., \& Tavares, G. (2008). Evaluation of research in efficiency and productivity: A survey and analysis of the first 30 years of scholarly literature in DEA. Journal of Socio-Economics Planning Science, 42(3), 151-157. https://doi.org/10.1016/j.seps.2007.07.002

Fa"re, R. \&. (1996b). Productivity and intermediate products:A frontier approach. Economics Letters, 50, 65-70. https://doi.org/10.1016/0165-1765(95)00729-6

Fa"re, R., \& \& Grosskopf, S. (1996a). Intertemporal production frontiers: with dynamic DEA. Boston: Kluwer. 10.1007/978-94-009-1816-0

Fa"re, R., \& Whittaker, G. (1995). An intermediate input model of dairy production using complex survey data. $J$ Agric Econ, 46, 201-213. https://doi.org/10.1111/j.1477-9552.1995.tb00766.x

Fare, R., \& Grosskopf, S. (2000). Network DEA. Socio-Economics Planning Sciences, 34(35-49). https://doi.org/10.1016/S0038-0121(99)00012-9

Hiller, F., \& Lieberman, G. (2001). Introduction to Operation Research. McGraw-Hill Series in Industrial Engineering and Management Science.

Hollingsworth, B. (2008). The measurement of efficiency and productvity of the health care delivery. Health Economics, 17(1107-1128). 10:1002/hec.1391

Kao, C. (2009(a)). Efficiency decomposition in network data envelopment analysis: A relational model. European Journal of Operational Research, 192(949-962). 10.1016/j.ejor.2007.10.008

Kao, C. (2009(b)). Efficiency measurement for parallel production systems. European Journal of Operational Research, 196, 1107-1112. https://doi.org/10.1016/j.ejor.2008.04.020

Kao, C. (2014). Efficiency decomposition for general multi-stage systems in data envelopment analysis. European Journal of Operational Research, 232, 117-124. Tratto da http://dx.doi.org/10.1016/j.ejor.2013.07.012

Kao, C. (2014). Network data envelopment analysis: A review. European Journal of Operational Research, 239(1), p. 1-16. https://doi.org/10.1016/j.ejor.2014.02.039

Kao, C., \& Hwang, S.-N. (2008). Efficiency decomposition in two-stage data envelopment analysis: An application to non-life insurance companies in Taiwan. European Journal of Operational Research, 185(418-429). 10.1016/j.ejor.2006.11.041

Kawaguchi, H., Tone, K., \& Tsutsui, M. (2014). Estimation of the efficiency of Japanese hospitals using dynamic and network Data envelopment Analysis model. Health Care Management Sciences, 17, 101-112. https://doi.org/10.1007/s10729-013-9248-9

Koopmans, T. (1951). An Analysis of Production as an Efficient Combination of Activities. In C. Koopmans, \& C. C. Economics (A cura di), Activity Analysis of Production and Allocation (Vol. 13). New York: John-Wiley and Sons, Inc.

Liu, J., Lu, L., Lu, W.-M., \& Lin, B. (2013). A survey of DEA applications. Omega, 41, 893-902. https://doi.org/10.1016/j.omega.2012.11.004

Pinto, C. (2016, March). The Acute Care Services Production Process's Efficiency: A DEA Network Model for the Italian Hospitals. Athens Journal of Health, 3(1). doi=10.30958/ajh.3-1-2

Pinto, C. (2019, March). Model and measure the relative efficiency of a four-stage production process. An NDEA multiplier relational model under different systems of resource distribution preferences between sub-processes. MPRA paper ( $N^{\circ}$ 92617). (Retrived from) 
Pinto, C. (2020). An NDEA Model as Policy Tool to Support Managerial Decisions. International Journal of Business Administration, 11(3).

Pinto, C. (2020). Performances Management When Modelling Internal Structure of a Production Process. International Journal of Business and Management, 7 (15), p. 133-146.

Prieto, A., \& Zofio, J. (2007). Network DEA efficiency in input-output models: With an application to OECD countries. European Journal of Operational Research, 178(1), 292-304. https://doi.org/10.1016/j.ejor.2006.01.015

Seiford, L. (1996). Data envelopment analysis:the evolution of the state of the art (1978-1995). Journa lof Productivity Analysis, 7, 99-137. https://doi.org/10.1007/BF00157037

Seiford, L., \& Zhu, J. (1999). Profitability and marketability of the top 55 US commercial banks. Management Sciences, 45, 1270-1288. https://doi.org/10.1287/mnsc.45.9.1270

Sexton, T., \& Lewis, H. (2003). Two-stage DEA: An application to Major League Baseball. Journal of Productivity Analysis, 19(2), 227-249. https://doi.org/10.1023/A:1022861618317

Wang, C., Gopal, S., \& Zionts, S. (1997). Use of data envelopment analysis in assessing information technology impact on firm performance. Ann Oper Res, 73, 191-213. https://doi.org/10.1023/A:1018977111455

Wanke, P., \& Barros, C. (2014). Two-stage DEA: An application to major Brazilian banks. Expert Systems with Applications, 41(5), 2337-2344. https://doi.org/10.1016/j.eswa.2013.09.031

Wanke, P., Maredza, A., \& Gupta, R. (2017). Merger and acquisitions in South African banking: A network DEA model. Research in International Business and Finance, 41, 362-376. https://doi.org/10.1016/j.ribaf.2017.04.055

\section{Notes}

Note 1. As in the DEA we can have a multiplier, envelopment and slacked NDEA models

Note 2 .To write: $\sum_{r=1}^{p} u_{r} Y_{r k}-\sum_{s=1}^{q} v_{i} X_{i k} \leq 0$ is the same that to write: $-\sum_{r=1}^{p} u_{r} Y_{r k}+\sum_{s=1}^{q} v_{i} X_{i k} \geq 0$,

Note 3. The function used in $\mathrm{R}$ is runif().

Note 4 . We decided to do so because our work at this step is not purely applicative.

Note 5. To run the correlation analysis in R we use the function "cor" with the option" use="complete.obs"', that eliminate all missing values in the observations

Note 6. The Wilcoxon-Mann-Whitney assume that the population distribution to which the sample are extract are not normally distributed, that the true population's variance is unknown and that the sample variance are homogeneous. This later hypothesis can be tested using the test $\mathrm{F}$ of Fisher.

Note 7. At this end we conduct five tests: 1) Jarque-Brera normality test 2) Shapiro-Wilk normality test 3) Lilliefors (Kolmogorov-Smirnov) normality test 4) Shapiro-Francia normality test 5) Pearson chi-square normality test.

Note 8. At this end we conduct the test $\mathrm{F}$ di Fisher.

Note 9. The null hypothesis in this case is: the mean of the relational efficiency under the preference system IV $\left(\mu_{I V}\right)$ is greater $(>)$ that the mean of the relational efficiency under all others preference systems.

\section{Copyrights}

Copyright for this article is retained by the author(s), with first publication rights granted to the journal.

This is an open-access article distributed under the terms and conditions of the Creative Commons Attribution license (http://creativecommons.org/licenses/by/4.0/). 